See Article page $\mathrm{XXX}$.

\section{Commentary: Are we living in the gilded age of treating mitral valve disease?}

\author{
Stephen H. McKellar, MD, MSc
}

The Gilded Age was a period of unprecedented technological growth and simultaneous wealth accumulation for a handful of moguls of industry in the United States between 1870 and 1900 . Although the era was marked by the expansion of technologies such as electricity into the lives of a broad section of citizens previously excluded, it came with the price of unprecedented market and political influence by the industrialists who benefited at the expense of average people.

There has never been a more exciting time for treating mitral valve disease. Diagnostic tests have never been better at diagnosing and providing essential information to guide treatment. Similarly, surgical and transcatheter repair techniques have never been safer or more effective than they are now: Extending treatment for patients previously too frail for conventional mitral valve surgery. Finally, postoperative or postprocedural outcomes have never been better or more completely understood. One might say we are living in the gilded age of treating mitral valve disease. Just like the Gilded Age had its downsides, so might our gilded age of treating mitral disease in the form of the myriad options available to clinicians and the associated confusion experienced by patients to make informed decisions.

In an attempt to define the unique advantages of surgical and transcatheter edge-to-edge repair, Okuno and colleagues ${ }^{2}$ report their dual-institution experience comparing surgical mitral valve repair and transcatheter edge-to-edge

\footnotetext{
From the Division of Cardiovascular and Thoracic Surgery, Intermountain Medical Center, Murray, Utah.

Disclosures: The author reported no conflicts of interest.

The Journal policy requires editors and reviewers to disclose conflicts of interest and to decline handling or reviewing manuscripts for which they may have a conflict of interest. The editors and reviewers of this article have no conflicts of interest.

Received for publication Aug 13, 2021; revisions received Aug 13, 2021; accepted for publication Aug 16, 2021.

Address for reprints: Stephen H. McKellar, MD, MSc, Division of Cardiovascular and Thoracic Surgery, Intermountain Medical Center, Eccles Outpatient Center, 5169 Cottonwood St, Suite 600, Murray, UT 84107 (E-mail: stephen.mckellar@imail. org).

J Thorac Cardiovasc Surg 2021

$: 1-2$

$0022-5223 / \$ 36.00$

Copyright (C) 2021 by The American Association for Thoracic Surgery

https://doi.org/10.1016/j.jtcvs.2021.08.036
}

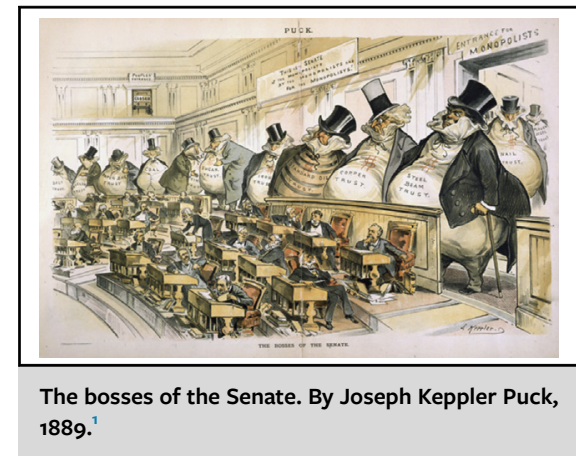

CENTRAL MESSAGE

Compared with transcatheter

edge-to-edge repair, surgical

mitral valve repair results in

greater reduction of mitral

regurgitation, improved LV func-

tion, and symptom-free survival.

repair in a propensity-matched cohort of patients with secondary (or functional) mitral regurgitation (MR). They identified 101 matched pairs and, at 2 years, observed similar mortality between the groups and greater reduction in MR, and improved left ventricular function and symptom-free survival in the surgical mitral valve repair cohort.

Whereas retrospective analyses have their limitations, including propensity-matched ones, they are useful and helpful, especially in generating hypotheses for more rigorous randomized, controlled, clinical trials. The current article $^{1}$ establishes the relationship between the degree of MR reduction and subsequent improvement in left ventricle function, which was dubious in the Cardiovascular Outcomes of the MitraClip Percutaneous Therapy for Heart Failure Patients With Functional Mitral Regurgitation (COAPT) and the Multicentre Study of Percutaneous Mitral Valve Repair MitraClip Device in Patients With Severe Secondary Mitral Regurgitation (MITRA-FR) trials. ${ }^{3,4}$ This association between degree of residual MR and reverse left ventricle remodeling are now testable hypotheses for clinical trials that could powerfully inform clinicians and patients on the best therapies to deploy for maximal long-term benefit.

Our current treatment paradigm for treating mitral valve disease consists of a $2 \times 2$ matrix consisting of both surgical mitral valve repair and replacement and both transcatheter 
mitral valve repair and replacement. As each technology is better understood, their unique advantages and disadvantages will be matched to the most appropriate patient populations, whether that is mitral stenosis, or primary MR, or secondary MR. This effort to establish appropriate clinical care pathways and firm therapeutic indications and contraindications must be based on good clinical science, and not industry influence, to avoid the trappings of the Gilded Age, during which undue industry influence benefited companies more than people.

\section{References}

1. Puck JK. The bosses of the Senate. 1889. Available at: https://www.senate.gov/artartifacts/historical-images/political-cartoons-caricatures/38_00392.htm. Accessed August 13, 2021.

2. Okuno T, Praz F, Kassar M, Biaggi P, Mihalj M, Kulling M, et al. Surgical versus transcatheter repair for secondary mitral regurgitation: a propensity-matched comparison. J Thorac Cardiovasc Surg. 2021. XX:XX-X.

3. Stone GW, Lindenfield J, Abraham WT, Kar S, Lim DS, Mishell JM, et al. Transcatheter mitral-valve repair in patients with heart failure. N Engl J Med. 2018;379: 2307-18.

4. Obadia JF, Messika-Zeitoun D, Leurent G, Iung B, Bonnet G, Piriou N, et al. Percutaneous repair or medical treatment for secondary mitral regurgitation. $N$ Engl J Med. 2018;379:2297-306. 